\title{
Review: antimicrobial prophylaxis reduces asymptomatic bacteriuria in patients with neurogenic bladder
}

Vickrey BG, Shekelle P, Morton S, et al. Prevention and management of urinary tract infections in paralyzed persons.

Rockville, MD: Agency for Health Care Policy and Research; February 1999; AHCPR publication no. 99-E008.

http://www.ahcpr.gov/clinic/utisumm.htm.

QUESTION: Does oral antimicrobial prophylaxis reduce the number of urinary tract infections (UTIs) in people with neurogenic bladder resulting from spinal cord dysfunction (SCD)?

\section{Data sources}

Studies of any language were identified by searching Medline (1966 to January 1998), EMBASE/Excerpta Medica (1974 to January 1998), and CINAHL (1982 to July 1998). Additional studies were identified by panel members and from bibliographies of relevant papers.

\section{Study selection}

Studies were selected if they were randomised controlled trials of adolescents and adults with neurogenic bladder resulting from SCD who received treatment to prevent recurrent UTI and the outcomes included asymptomatic (bacteriuria) or symptomatic UTI.

\section{Data extraction}

Data were extracted on study population, specific treatments, group size, outcomes measured, and results. Main outcome was weekly infection rate, which was estimated for each study comparison.

\section{Main results}

19 studies met the inclusion criteria. Meta-analyses were done for 4 strata according to time from injury (acute $[<90 \mathrm{~d}]$ or non-acute $[\geq 90 \mathrm{~d}])$ and type of infection (symptomatic or asymptomatic). Antimicrobial prophylaxis showed a greater reduction in the weekly infection rate than did no antibiotic prophylaxis but only for the stratum of acutely injured patients with asymptomatic infection (table). 4 studies reported on the proportion of antimicrobial resistant organisms cultured in treatment versus no treatment groups; 3 studies reported a $\geq 2$-fold increase in the proportion of antimicrobial resistant organisms cultured from the treatment groups, and 1 older study reported no resistant organisms cultured from either group (no statistical analysis provided).

\section{Conclusions}

Oral antimicrobial prophylaxis reduces asymptomatic urinary tract infections in patients with acute neurogenic bladder resulting from recent spinal cord dysfunction and shows a similar trend $(\mathrm{p}=0.06)$ in patients with non-acute injury. According to the authors, the risk for developing antimicrobial resistant organisms may increase with antimicrobial prophylaxis.

\section{COMMENTARY}

UTIs with resulting lithiasis and loss of renal function have been a major source of secondary disability, morbidity, and mortality in patients with neurogenic bladder resulting from SCD or demyelination. Improvement in the quantity and quality of life for people with spinal injuries over the past 60 years is, in no small part, a result of progress in the management of the neurogenic bladder. Although a broad consensus exists about the need to treat symptomatic UTIs in these patients, the role of antimicrobial chemoprophylaxis to prevent UTIs in the first place is less well established. The systematic review by Vickrey $e t$ al attempts to shed some light on this area. Nevertheless, a definitive answer has not yet been provided.

The meta-analysis shows that antimicrobial chemoprophylaxis reduces the prevalence of asymptomatic infection (ie, bacteriuria). It fails to show a similar effect on the occurrence of symptomatic infection. This latter finding might be related to a lower incidence of symptomatic infection and therefore a higher chance for inadequate statistical power. The reported confidence intervals indicate that the results may still be consistent with a clinically relevant benefit.

The relatively low incidence of symptomatic UTIs, together with some evidence suggesting the emergence of antimicrobial resistance, may constitute an argument to refrain from the routine use of antimicrobial chemoprophylaxis. Unfortunately, given the serious sequelae of chronic UTIs, we still need to await the results of large, multicentre disease management studies before we will know how to optimally treat patients with neurogenic bladders.

Ralph Bloch, MD University of Berne Berne, Switzerland

Antimicrobial prophylaxis $v$ no prophylaxis for asymptomatic and symptomatic weekly rates of urinary tract infection in patients with acute and nonacute spinal cord dysfunction*

\begin{tabular}{llllll}
$\begin{array}{l}\text { Injury/outcome } \\
\text { Acute/asymptomatic }\end{array}$ & 6 & $\begin{array}{l}\text { Number of } \\
\text { studies }\end{array}$ & $\begin{array}{l}\text { Control group infection } \\
\text { rates }(95 \% \mathrm{Cl})\end{array}$ & $\begin{array}{l}\text { Change in weekly rate with } \\
\text { treatment }(\mathrm{CI}) \text { 1 infection }\end{array}$ & $\begin{array}{l}\text { Weeks of prophylaxis } \\
\text { to prevent }\end{array}$ \\
\hline Acute/symptomatic & 2 & $0.52(0.27$ to 0.77$)$ & $-0.27(-0.40$ to -0.15$)$ & 3.7 \\
\hline Non-acute/asymptomatic & 6 & $0.04(0.00$ to 0.09$)$ & $-0.03(-0.08$ to 0.02$)$ & NS & NS \\
\hline Non-acute/symptomatic & 4 & $0.33(0.14$ to 0.51$)$ & $-0.06(-0.12$ to 0.00$)$ & NS \\
\hline${ }^{*}$ NS = not significant. Other abbreviations defined in glossary.
\end{tabular}

${ }^{*} \mathrm{NS}=$ not significant. Other abbreviations defined in glossary.
Source of funding: Agency for Health Care

For correspondence: $\operatorname{Dr} B$ G Vickrey and $\operatorname{Dr}$ P Shekelle, Southern California

Evidence-Based Practice Center, RAND, 1700 Main Street, Santa Monica, $C A$ 90401, USA.Fax +1 3104516930. 